\title{
Modelling Customer Engagement Behaviour in Smart Retailing
}

\author{
Sanjit K. Roy \\ Univeristy of Western Australia, Perth, Australia \\ sanjit.roy@uwa.edu.au
}

\section{Gaganpreet Singh}

OP Jindal Global University, India

\section{Saadia Shabnam}

Curtin University, Perth, Australia

\section{Abstract}

Smart retail technologies are transforming the way companies engage with customers in retailing context. However, the real onset is unknown of which smart retail technology (SRT) characteristics and customer responses pave the way for customer engagement behaviour. This research investigates customer engagement behaviour in smart retailing by integrating meta-UTAUT and SRT characteristics. By analysing quantitative survey data using PLS path modelling, customer engagement manifestations are measured. Results show complex relationships between SRT characteristics (novelty, effectiveness, and interaction quality) and meta-UTAUT variables (performance expectancy, effort expectancy, social influence, and facilitating conditions) in influencing customers' attitude, behavioural intention, and engagement behaviour towards smart retailing. Retailers can use the findings to influence customers' attitudes towards smart retail technologies, encouraging them to display customer engagement behaviour.

Keywords: Customer engagement behaviour, Smart retailing, Smart services, meta-UTAUT, Social influence

\section{Introduction}

The massive infusion of new in-store retail technologies is making customer engagement increasingly challenging (Grewal et al., 2020a). In-store retail technologies are most commonly employed to transform retail stores' engagement with their customers (Ferracuti et al., 2019; Grewal et al., 2018). Smart retail technologies (hereafter, SRT) refers to an interactive and connected retail system that involves the effective management of different customer touchpoints to improve customer experience and enhance performance across these touchpoints (Roy et al., 2017). For instance, self-service technologies, interactive displays, touch screens, virtual shelves, in-store mobile apps, self-check-out functionality (Amazon Go), and informative touchpoints influence customer engagement in retail stores (Fan et al., 2020, Adapa et al., 2020). With global retail sales projected to reach approximately 26.7 trillion U.S. dollars by 2022, up from 23.6 trillion U.S. dollars in 2018 (Liam O'Connell, 2020), retailers are in a constant search to explore SRT with notable characteristics that may significantly influence consumer behaviour during the in-store interaction (Grewal et al., 2020a). Prior studies in the Information systems (IS) and marketing literature have investigated the impact of several SRT characteristics on customers' perceived value (Adapa et al., 2020; Karjaluoto et al., 2019; Shaw and Sergueeva, 2019), shopping experience (Roy et al., 2017), intention to use SRT (Roy et al., 2018a), value co-creation (Knote et al., 2020), and retail engagement (Fan et al., 2020). However, 
there is limited research investigating the role SRT characteristics play in driving customer engagement behaviour (hereafter, CEB) (Wang, 2020). CEB has received increased academic and practitioner attention because of its essential contribution to firm performance in terms of profitability and sustainable competitive advantage (Hollebeek et al., 2016). Given its importance, the Marketing Science Institute also highlights customer engagement drivers as a research priority for 2018-2020 (MSI, 2018).

Extant research in IS literature focuses on the customer-smart object circumplex (Novak and Hoffman, 2019, Knote et al., 2020), technology characteristics as an object of customer engagement (Pöyry et al., 2020), and customers' cognitive and emotional engagement as the drivers of CEB towards SRT (Fan et al., 2020). However, limited research attention has gone into empirically examining the impact of technology attributes and contextual factors on CEB towards SRT. Drawing from the meta-unified theory of acceptance and use of technology (meta-UTAUT) in the IS literature, this study considers performance expectancy and effort expectancy as technology attributes (TA) and facilitating conditions and social influence as contextual factors (CF) (Dwivedi et al., 2019; Karjaluoto et al, 2019; Shaw and Sergueeva, 2019). In addition, service convenience is recommended as an essential driver of CEB (Roy et al., $2020 \mathrm{~b}$ ). We argue that the TA (i.e., performance expectancy and effort expectancy) would offer customers a considerable gain and convenience, thereby, capable of influencing CEB towards SRT. Similarly, an individual's engagement toward SRT may also be influenced by important people in their social network, i.e., family, friends, colleagues, and their opinion (Baishya and Samalia, 2020; Venkatesh et al., 2012). Specifically, it is assumed that people can perform a specific behaviour if they believe that one or more of the crucial referents think they should (Peng et al., 2017). Hence, we argue that social influence and facilitating conditions will influence CEB towards SRT. Based on the propositions of Dwivedi et al. (2019; 2020), this study examines the role of customers' attitude and behavioural intention towards SRT in influencing CEB. Most importantly this study extends the meta-UTAUT by examining the influence of SRT characteristics such as novelty, effectiveness, and interaction quality on TA and CF to form customers' attitudes towards SRT (Adapa et al., 2020; Roy et al., 2020a). Based on the preceding discussion, this study has threefold objectives:

1. To examine the role of attitude and behavioural intention in influencing customers' engagement behaviour towards SRT.

2. To examine the impact of TA (i.e., performance expectancy, effort expectancy), and CF (i.e., social influence, facilitating conditions) on customers' attitude towards SRT.

3. To examine the influence of SRT characteristics (novelty, effectiveness, interaction quality) on TA and CF.

Given that traditional retailing is now experiencing severe challenges from online retailers (Chiu et al., 2011), in-store SRT can be introduced as an effective strategy to offer a unique instore customer experience (Grewal et al., 2020a; Kim et al., 2017) and thus reduce the threat of customer churn. However, with SRT implementation still in the growth phase, several in-store retailers are still anxious about its ability to influence CEB towards SRT.

We chose the meta-UTAUT (Dwivedi et al., 2019) over the original Unified Theory of Acceptance and Use of Technology (UTAUT) as the overarching theoretical framework because of its strengths. First, the original UTAUT model was short of attributes on 'individuals' who engaged with technology and were significant in describing their 
dispositions towards the use of underlying technology. Dwivedi et al.'s (2019) revised model (meta-UTAUT) incorporated and tested the influence of attitude as a mediating construct using meta analytic structural equation modelling with data collected from 162 prior UTAUT based studies. The results revealed that attitude partially mediated the effects of all four UTAUT exogenous variables on behavioural intention. In addition, the inclusion of attitude increased the explanatory power on the model significantly to $45 \%$, from $38 \%$ without attitude (Dwivedi et al., 2019). Second, the current study did not test the influence of any moderating variable. This is consistent with the recommendations of meta-UTAUT which does not advocate a mandatory role of any moderating variable as moderators may not be unanimously applicable in different contexts (Dwivedi et al., 2020). Hence, meta-UTAUT is considered to be a meaningful alternative for the UTAUT model in understanding acceptance, usage, and behaviour towards technology (Dwivedi et al., 2020).

While previous studies have investigated the role of customer engagement in driving CEB towards SRT (Fan et al., 2020; Baldus et al., 2015; Vivek et al., 2012), this study contributes to the body of knowledge by investigating the determinants of CEB towards SRT. The current research deviates and contributes to the IS literature by examining the direct and mediating effect of customers' attitudes in influencing CEB towards SRT. Also, this study validates the role of UTAUT variables (performance expectancy, effort expectancy, social influence, and facilitating conditions) in influencing customers' attitude towards SRT. The study contributes to the existing literature by investigating the antecedents capable of influencing customers' attitude towards SRT (Roy et al., 2018a; Vahdat et al., 2020). Besides, the results also contribute to the ongoing debate on SRT characteristics that impacts customer behaviour (Adapa et al., 2020). Overall, this study responds to the need for further research on investigating customers' engagement and its associated behaviour with technologies including SRT (Grewal et al., 2020a; Wang 2020; Adapa et al., 2020).

The rest of the paper is organised as follows. Section two provides a literature review and theoretical background and explains the research model proposed in this study. Next, the research methods, operationalisation of constructs, data collection, and sampling are discussed. Finally, we present the findings of the study, followed by the theoretical and managerial implications and discuss the limitations and future research directions.

\section{Literature review}

\subsection{Smart retailing}

Smart retailing refers to "an interactive and connected retail system which supports the seamless management of different customer touchpoints to personalise the customer experience across different touchpoints and optimise performance over these touchpoints" (Roy et al., 2017 p.3). Smart retailing differs from other traditional technologies, including eretailing based on several characteristics and attributes (Kabadyi et al., 2019). While the former incorporates interactions among the customers; smart objects, products (brands), retailer, and retail channel (touchpoints), the latter technologies are limited to retail channels (touchpoints) and a dyadic interaction (between firm and customers) (Foroudi et al., 2018; Roy et al., 2017). Also, the traditional services as human-centred processes involve value creation through the interaction of two or more actors (individuals, organisations, or public authorities). However, in the context of smart services, the focus shifts towards the value creation at the time of human-technology interaction (Knote et al., 2020). Moreover, smart retailing offers a greater 
sense of flexibility relative to the traditional retailing. Also, the ability of smart retailing to connect both the physical and digital worlds enables real-time interaction with the customers (Gregory, 2016).

Smart retailing involves the transformation of both front-and-back ends of the traditional instore retail spaces through mobile applications and contactless, omnichannel, ubiquitous technology (Vazquez et al., 2017). The transformation at the front end involves the incorporation of the Internet of things, intelligent application shelves, and intelligent hardware (Roy et al., 2018a), thereby reimagining the customers' in-store experience. The transformation at the backend involves the digital platform to ensure connectivity based on "network logic" to support omnichannel marketing (Wu and Cheng, 2018). Hence, SRT holistically improves the perception, communication, and computing power of offline retailing (Fan et al., 2020). For instance, Nike has launched touchpads to pay for products, wall screens to encourage customers to engage with the catalogue, QR codes to memorise a product, and smartphones to test the Nike mobile app (Attié et al., 2020). The ability of SRT to provide perceived flexibility in comparison to traditional retailing (Roy et al., 2017) is expectedly transforming the customer behaviour throughout the decision process stages, i.e., search, purchase, consumption, and after-sales (Vrontis et al., 2017). The application of SRT demands organisations to acquire new competencies to monitor, control, optimise the operations more effectively. Such competencies require marketers to regularly examine SRT characteristics that may assist in the development of an enabling environment where the smart retailers and the customers interact with each other. Therefore, investigating the influence of SRT characteristics such as novelty, effectiveness, and interaction quality on TA and CF in shaping customers' attitudes towards SRT becomes imperative.

\subsection{Customer engagement behaviour (CEB)}

The concept of customer engagement has recently received substantial attention both in academia and industry (Precourt, 2016; Hollebeek et al., 2019). CEB is viewed as an accumulation of the techniques through which customers engage in the company's activities apart from just restricted to purchase (Brodie et al., 2011; Jaakkola and Alexander, 2014). From the customers' perspective, CEB is defined as "customers behavioural manifestations towards the brand or firm, beyond purchase, resulting from motivational drivers" (Van Doorn et al., 2010). This concept also supports the S-D logic informed definition of CEB (Hollebeek et al., 2019) where authors argued that consumers deploy their competencies, interact to co-create, and phenomenologically determine the service value. CEB assumes customers as an exogenous entity whose behaviour in a smart retail setting may be deemed as being persuaded by both the in-store retail environments and their action and intention driving responses towards smart retailing (Vivek et al., 2012). For instance, organisations offer significant investments in providing engagement platforms to customers through the online brand community (Baldus et al., 2015), and through other interactive technologies.

Similarly, customers invest their resources (money, time, and effort) as a part of their effort towards CEB (Van Doorn et al., 2010). Consistent with previous research (Ángeles OviedoGarcía et al., 2014; Islam and Rahman, 2016; Jaakkola and Alexander, 2014; Van Doorn et al., 2010), this study considers CEB as one-dimensional construct because it captures the behavioural manifestation of consumers interacting with smart technologies in retail stores. This conceptualisation clarifies the context-dependent nature of customers' expressions, such 
as their engagement which tend to develop over time under conducive smart service context and favourable smart service experience (Brodie et al., 2011).

The preceding discussion indicates that there is a need to address the impact of SRT characteristics and consumers affective responses to increase the likelihood of CEB in smart retailing context (Adapa et al., 2020; Grewal et al., 2020a; Wang 2020). The following section presents the research model and specifies the relationships between variables in the model.

\section{The Research Model}

The research model proposed (see Figure 1) in this study adopts the (meta-UTAUT) theory (Dwivedi et al., 2019) as an overarching framework and provides a holistic framework for determining CEB towards SRT. Prior research in the relevant domain has examined customer attitudes and behaviours towards SRT by integrating several theories, such as the technology acceptance model (Davis 1989) technology readiness perspective, and organisational theory (Roy et al., 2018a) etc. The current study uses the meta-UTAUT model for its superior predictive validity compared to other technology usage models (Tamilmani et al., 2020; Dwivedi et al., 2020). We extended the meta-UTAUT to incorporate SRT characteristics, namely, SRT novelty, SRT effectiveness, and SRT interaction quality. The proposed research model examines the impact of SRT characteristics (e.g., novelty, effectiveness, and interaction quality) on customers affective responses measured through the UTAUT factors (e.g., TA (i.e., performance expectancy and effort expectancy), and CF (social influence and facilitating conditions). Further, the study models the impact of affective responses on customers' attitudes toward and intention for CEB towards SRT.

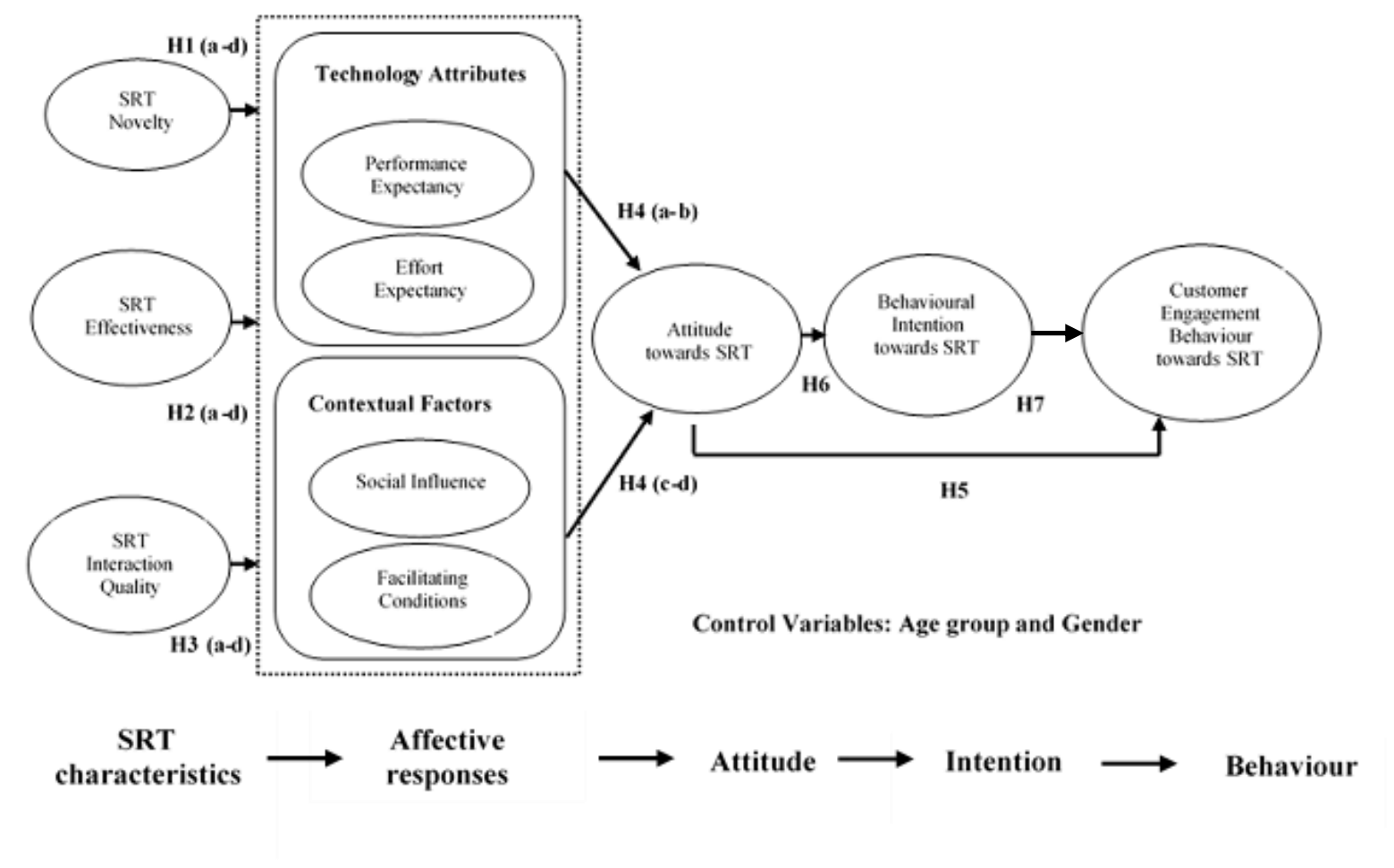

Figure 1. Research model 


\section{Research Hypotheses}

\subsection{Relating SRT characteristics and UTAUT variables}

\subsubsection{SRT novelty, technology attributes, and contextual factors}

The novelty of SRT refers to the degree to which customers perceive SRT as exclusive for its innovativeness to contribute to accomplish their shopping goals more enjoyably (Adapa et al., 2020) and satisfy their desire for newness (Leroi-Werelds, 2019). Customers' perception of novelty is subjective; hence, can manifest in different ways and must, therefore, be carefully examined (Blythe, 1999). Prior literature suggests that novelty characteristics of any service offered cause either positive or negative affective reactions (Wells et al., 2010). These affective responses evolve because customers perceive novelty as either something they have never experienced before or as previously experienced attributes that are presented in unprecedented combinations (Wells et al., 2010). The ability of SRT to offer customers with enhanced convenience, experience, value, and engagement, over traditional retailing triggers several positive affective responses among customers (Roy et al., 2017, Fan et al., 2020). Also, the increased interactivity in SRT allows the customers to shop with ease (Roy et al., 2017). These positive outcomes are possible because the perceived benefit of shopping through SRT outweighs the costs associated with maintaining the status quo. Thus, we advance the following hypotheses:

H1 (a-b) SRT novelty positively influences technology attributes (performance expectancy and effort expectancy).

H1 (c-d) SRT novelty positively influences contextual factors (social influence and facilitating conditions).

\subsubsection{SRT effectiveness, technology attributes, and contextual factors}

SRT effectiveness refers to the extent to which customers perceive SRT's contribution to their shopping goals and eventually improves their overall shopping experience (Roy et al., 2020a). Customers perceive an increase in effectiveness when they can perform a transaction with increasing speed, control, and convenience (Collier et al., 2015; De Keyser et al., 2020) when shopping via SRT. The ability of SRT to leverage improved experience enhances customers' shopping satisfaction and ultimately increases their shopping effectiveness (Roy et al., 2017). In addition to that, smart customer experience also reduces customers' perceived risk towards SRT, thereby, also increasing their shopping effectiveness (Roy et al., 2017). The ability of SRT to allow customers to accomplish their shopping tasks with efficiency and ease will impact customers' affective behaviour (Overby and Lee, 2004). The SRT effectiveness is likely to influence customers' perceptions of the resources and support available by the smart retailer to perform a behaviour (Brown and Venkatesh, 2005; Collier et al., 2015; De Keyser et al. 2020). Therefore, we advance the following hypotheses:

H2 (a-b) SRT effectiveness positively influences technology attributes (performance expectancy and effort expectancy).

H2 (c-d) SRT effectiveness positively influences contextual factors (social influence and facilitating conditions). 


\subsubsection{SRT interaction quality, technology attributes, and contextual factors}

SRT interaction quality is customers' perception toward any specific event of interaction with the SRT, which takes into account the environmental elements in the store. The quality of interaction thus fosters individuals' engagement levels throughout a specific event of interaction and generate certain affective responses (Bejerholm and Eklund, 2007). In smart retailing, the interactions between customers and SRT occurs in several ways. These include interactions among the customers, smart objects, products (brands), retailers, and retail channels (touchpoints) (Roy et al., 2017; Knote et al., 2020). When customers interact with technology including SRT, their overall interaction quality is contingent on factors such as information content quality (Park et al., 2008), system quality, and service quality (Shin, 2015) or a combination thereof. The information quality is determined by both the informativeness and entertainment ability of the technology (Negash et al., 2003). The former deals with information accuracy, relevance, timeliness, convenience, and completeness. The latter discusses the ability of the technological interface to be entertaining, enjoyable, pleasing, fun, and exciting for customers (Negash et al., 2003). The system quality is assessed by the interactivity and the accessibility of the technology. Interactivity refers to the degree to which customers can participate in altering the form and content of a media-based environment in real-time. Access refers to the ease of using and accessing the interface while extracting the information (Negash et al., 2003). The quality interactions and information-sharing mechanisms may subsequently tender social influence on one another (Bapna and Umyarov, 2015). Also, the quality system may serve as platforms for facilitating interactions with and among customers (Viswanathan et al., 2017; Grewal et al., 2020b). Based on the preceding discussion, we propose the following hypotheses:

H3 (a-b) SRT interaction quality positively influences technology attributes (performance expectancy and effort expectancy).

H3 (c-d) SRT interaction quality positively influences contextual factors (social influence and facilitating conditions).

\subsection{Relating UTAUT variables (technology attributes and contextual variables) and attitude towards SRT}

\subsubsection{Performance expectancy and attitude towards SRT}

Performance expectancy is defined as the degree to which an individual believes that SRT will assist them in achieving gains (Venkatesh et al., 2003). We draw upon the equity theory (Adams, 1963) to examine customer attitude towards and their behavioural intention towards SRT. According to this theory, customers would engage with new technology, including SRT depending on their gain/effort ratio. Customers will view the technology with more optimism and develop a positive attitude if their engagement would accrue higher gains than their efforts (Evanschitzky et al., 2015). On the contrary, customers will develop negative attitudes when the benefits of new technology are observed by retailers at shoppers' expense (Inman and Nikolova, 2017; Grewal and Roggeveen, 2020). Therefore, we propose the following hypothesis:

H4 (a) Performance expectancy positively influences attitude towards SRT.

\subsubsection{Effort expectancy and attitude towards SRT}

Effort expectancy is defined as "the degree of ease associated with customers' use of technology" (Venkatesh et al., 2012, p. 159). Customers' desire to adopt new technology is not 
only envisaged by the associated positive values, but also by the ease and free efforts with which individuals can operate this, plays an essential role (Davis, 1989). Due to the specific nature of SRT, customers need to acquaint themselves with a certain level of knowledge and skill. Hence, effort expectancy could play a vital role in determining customers' attitudes towards SRT. Customers may perceive difficulty in using SRT since it entails a higher level of customer involvement compared to their limited involvement in the full-service option. For instance, a struggle to handle smart retailing mobile application may act as one of the vital dimensions of complexity (Inman and Nikolova, 2017; Grewal et al., 2020b). Also, personality characteristics, such as inertia, or the desire for human interaction (White et al., 2012) are likely to contribute to customers' perceived difficulty to use new technologies including SRT (Meuter et al., 2000). Moreover, customers may perceive the information overload as complex (Iyengar and Lepper, 2000). While some customers may perceive the extra effort as only marginal, others may feel it burdensome and thus form an unfavourable attitude towards SRT. Based on the preceding discussion, we advance the following hypothesis:

H4 (b) Effort expectancy positively influences attitude towards SRT.

\subsubsection{Social influence and attitude towards SRT}

According to the UTAUT model, social influence is characterised as "the degree to which an individual perceives that important others believe he or she should use the new system" (Venkatesh et al., 2003 p 451). This explanation incorporates two dimensions, namely subjective norm and descriptive norm. The former defines an individual's perception of other expectations (compliance), and the latter refers to the perception of attitudes possessed by significant others' behaviours (Wang and Lin, 2011). Besides, the literature proposes that the demonstrability of several people's actions is significant to persuade a single individual's behaviour (Elek et al., 2006). This implies an individual is likely to believe certain behaviour as sensible when they observe that many others are following it. Previous research suggests that, when the customer selects to either accept or resist new technology, including SRT, they also consider the effects of this selection on their relationship with others. Hence, customers incline to conform to the majority decision (Qin et al., 2011). In this context, conformity may be assumed as personal acceptance leading to private attitudinal change (Book et al., 2018). Normative conformity might also be invoked through social norms, which sees individuals decides to act while considering the expected or acceptable behaviour in social interactions (Knoll et al., 2015). Individual compliance with expectations or social norms, thus, encourages them to execute an action if they perceive of gaining greater social influence in return (Talukder and Quazi, 2011). It is argued that public opinion plays a vital role in impacting individuals' attitude towards a given technology (Kang, 2014). Likewise, with increasing technology diffusion, probable adopters are more likely to observe the technology in use, which may encourage them to believe it is useful (Graf-Vlachy et al., 2018). Therefore, it is expected that customers' attitudes towards SRT may be affected when they perceive many others using it, especially in their social groups (Carter and Yeo, 2016; Roggeveen et al., 2020). Thus, we propose the following hypothesis:

H4 (c) Social influence positively influences attitude towards SRT.

\subsubsection{Facilitating conditions and attitude towards SRT}

Facilitating conditions are defined as "the degree to which an individual believes that an organisational and technical infrastructure exists to support the use of the system" (Venkatesh et al., 2003 p 453). In other words, facilitating conditions can be viewed as customer perception 
about the availability of resources that enhance their use of technology (Hossain et al., 2017). Dwivedi et al. (2019) theorised that facilitating conditions has a significant influence on customers' attitude. This implies that facilitating conditions such as assistance centres and training programs for using the technology may act as vital enablers in influencing customers' attitudes (Dwivedi et al., 2019; Sabharwal et al., 2006; Grewal et al., 2020a). In the context of SRT, facilitating conditions may include the presence of intelligent systems, human-machine interactions, self-service, and product content quality (Fan et al., 2020; Roggeveen et al., 2020). These facilitating conditions impact customers' smart experience quality and eventually influence their attitude towards SRT. Based on the proceeding discussion and empirical evidence, we hypothesise the following:

H4 (d) Facilitating conditions positively influences attitude towards SRT.

\subsection{Influence of attitude towards SRT and CEB}

Attitude refers to an individual's positive or negative feelings about performing the target behaviour (Davis 1989; Taylor and Todd 1995). Customers attitude plays a key role in determining their acceptance and use of technology, including SRT. Dwivedi et al. (2019) hypothesised behavioural intention to mediate the effect of attitude on usage behaviour. However, their meta-analysis results revealed that attitude has a direct impact on customer usage behaviour as well. This signifies that attitude may significantly influence behaviour even though the customer may not intend to use the technology. Existing literature indicates, the influence of behavioural intention on usage behaviour may not be particularly strong or predictable (Pardamean and Susanto 2012; Weerakkody et al., 2013), which further emphasises the significance of the direct effect between attitude and usage behaviour. Therefore, we argue that customers with a positive attitude towards SRT will be influenced to help organisations and customers directly and indirectly beyond the purchase process (Grewal and Roggeveen, 2020). Based on the proceeding discussion and theoretical conceptualisation by Dwivedi et al. (2019), we hypothesise the following:

H5 Attitude towards SRT positively influences CEB towards SRT.

\subsection{The mediating role of attitude towards SRT}

The four exogenous constructs in the meta-UTAUT (i.e., technology attributes and contextual factors) represent customer perceptions regarding the technology and the context. Though there exists significant evidence that these four constructs explain a significant proportion of variance in customer adoption and usage behaviours, UTAUT excluded several key individual characteristics that describe customers' disposition in influencing their behaviours. Customers' attitude is one of the several such individual aspects (Chong 2013; Venkatesh et al., 2011). Realising the importance, Dwivedi et al., (2019) recommended the inclusion of customer attitude in examining customer behaviour towards technology. The inclusion of attitude in models of technology acceptance is consistent with the theory of reasoned action and the theory of planned behaviour (Ajzen, 1991). We position attitude as a mediator between performance expectancy, effort expectancy, social influence, facilitating conditions, and CEB towards SRT. This is because an individual's attitude may be shaped by perceived usefulness (Vahdat et al., 2020); perceived ease of use, and superior functionality (Roy et al., 2018a). In other words, technology capabilities may influence customers' attitudes towards SRT. Also, facilitating conditions such as technology readiness (Roy et al., 2018a) and social influence (Vahdat et al., 2020; Roggeveen et al., 2020), which are contextual factors may also influence 
customers' attitude towards SRT. Therefore, it is expected that customers' attitudes towards SRT will influence them to involve in engagement behaviour towards SRT. Based on the above discussion and empirical evidence, we propose the following hypothesis:

H6: Attitude towards SRT mediates the relationship between technology attributes (e.g., performance expectancy and effort expectancy) and contextual factors (e.g., social influence and facilitating conditions) and CEB.

\subsection{The mediating role of behavioural intention towards SRT}

In addition to attitude, researchers also identified the influence of the behavioural intention on actual behaviour (Bagozzi and Yi, 1989; Bhattacharjee and Sanford, 2009). We also argue that only customers' positive attitude may not be sufficient to encourage customers to voluntarily contribute their resources (time, money, and effort) to help organisations and other customers through CEB (Jaakkola and Alexander, 2014; Wang, 2020). Customers' willingness and effort, thus the intention to perform the underlying behaviour is imperative (Ajzen, 2011). As the theory of planned behaviour (TPB) and theory of reasoned action (TRA) argues that stronger the intentions, the higher is the probability of performing the underlying behaviour (Fishbein and Ajzen, 1975; Ajzen, 1991). Hence, it can be argued that individual behaviour is driven by their behavioural intention, which is, in turn, a function of an individual's attitude towards the behaviour (Ajzen, 2011). Based on the preceding discussion we propose the following hypothesis:

H7 Behavioural intention towards SRT mediates the relationship between attitude towards SRT and CEB.

\subsection{Control Variables}

According to the prior literature, certain demographic variables can influence key constructs examined in this study. Hence, to allow for better delineation of the relationship proposed in our model and to provide a more rigorous test of the theoretical linkages, we included demographic variables, such as age group, and gender as control variables. This helps to account for respondent heterogeneity and avoid any confounding influences on the results. Controlling for these variables will enhance the generalisability of the study findings (Balaji and Roy, 2017).

\section{Methodology}

\subsection{Research Context}

Retailing is one of the major sectors in the Australian economy comprising of various subsectors including consumer goods and supermarket retailing. It contributes approximately $9 \%$ to the Australian GDP per annum (Roy et al., 2019). The supermarkets and grocery market together make up $\$ 103$ billion approximately in Australia. Out of this, Woolworths and Coles accounted for over $65 \%$ of industry revenue in 2018 (IBIS World, 2018). In the changing retail landscape as a result of technology infusion, it is expected that traditional retailers will need to adapt their marketing strategies and business models to stay competitive (Magner, 2016). Various industry reports suggest that the Australian retail industry is undergoing a major transformation with the infusion of new technologies in service delivery (Australian Retailers Association, 2020). 
Smart retailing in Australia is the research context for this study to examine CEB towards SRT. The ability of the Internet of Things (IoT) to institute transformational changes and hypercompetition encourages traditional retailers to periodically incorporate new technological innovations for growth and efficiency (Caro and Sadr, 2019; Roy et al., 2019). Smart retailing (e.g., smart shopping carts, shopping assistants, near field communications, smart payment systems, and AI-based technologies) is one such common business transformation practice adopted by the retailers. Smart retailing incorporates multiple interactions (Roy et al., 2017). These interactions influence customer outcome variables, including word-of-mouth, purchase loyalty (Fan et al., 2020; Roy et al., 2017). Therefore, smart retailing becomes one of the ideal contexts to examine CEB. Also, due to the general lack of studies focused on CEB towards SRT, the effects of technology attributes and contextual factors have been overlooked. Therefore, it is imperative to study what influences the CEB explicitly towards SRT.

\subsection{Sample and data collection}

The web-based survey data was collected in Australia using Qualtrics. Potential respondents were invited to participate through a web-link coupled with a survey questionnaire along with small incentives. Data was collected in the second quarter of 2019. The services of a market research company were availed to collect data. The consumer panel members were directed to respond to the survey on SRT in the retailing context. The market research agency used a quota-based approach to ensure that the respondents represented the population of interest in Australia as closely as possible. Upon agreeing to participate, respondents were requested to complete the questionnaire. The questionnaire contained measurement items of SRT novelty, SRT effectiveness, SRT interaction quality, performance expectancy, effort expectancy, social influence, facilitating conditions, attitude towards SRT, behavioural intention towards SRT, CEB and question on demographics. The respondents were duly informed to consider their most recent experience with SRT (i.e., within the last six months) as a reference stimulus while responding to the questionnaire. Industry reports and prior literature was referred to develop a shared understanding of customer facing SRT (Gregory, 2016, Willems et al., 2017). Smart checkouts, personal shopping assistance, point-of-sale smart displays, NFC systems, and augmented reality were some of the commonly reported SRTs in the questionnaire.

A total of 293 valid responses were obtained with a response rate of $45 \%$. Soper's (2014) sample size calculator was used to calculate the minimum sample size requirement. The minimum sample recommended for structural equation modelling with ten latent variables, 40 observed variables, p-level, 0.05, and anticipated size effect, 0.03 is 100 (Soper's (2014). The study met the sample size criterion to model the structure. The $t$-tests did not reveal significant differences in the study constructs for the early and late response groups, eliminating the concern of non-response bias in this study. The sample had: (1) gender: $45 \%$ of respondents were male and 55\% were female; (2) age group: 56\% of respondents were in $21-35$ age group, representing a comparatively younger group of customers; and (3) education level: $54 \%$ of respondents had bachelor's degree.

\subsection{Measurement Instrument}

The constructs in this study were measured using validated items from the prior literature (see Appendix A). The three SRT characteristics (SRT novelty, SRT effectiveness, and SRT interaction quality) were measured using items proposed by O'Brien and Crains, (2015) Collier et al., (2015), and Brady and Cronin, (2001) respectively. The affective responses representing the dimensions of UTAUT (performance expectancy, effort expectancy, facilitating conditions, 
and social influence) were measured using items suggested by Zhou et al., (2010), and Kaushik and Rahman, (2015). Attitude towards SRT consisted of three 7-point semantic differential items adapted from Weijters et al., (2007). The CEB was measured using items suggested by Yi et al., (2013) and Balaji (2014). Responses to all the questions were measured using a 7- point Likert scale anchored at "strongly disagree (1)" to "strongly agree (7)". The draft questionnaire was evaluated, and pilot tested with fifty students to check for any ambiguous sentence wording or expressions. The feedback received from the pilot study was included in the questionnaire, and the final questionnaire was then administered to actual retail shoppers in Australia by a market research firm.

\section{Data Analysis}

Partial least squares path modelling (PLS-PM) using SmartPLS 3.0 (Ringle et al., 2015) was selected to analyse the data. The reasons to choose PLS-PM include: PLS-PM can effectively manage non-normal data, unlike covariance-based structural equation modelling (Lowry and Gaskin, 2014). PLS-PM can proficiently handle complex predictive models by maximising the variance explained in the ultimate dependent variable (Sarstedt et al., 2020). The use of PLSPM was suitable for this study because of its exploratory nature, its complex and predictionoriented model, the likelihood that the items would not be normally distributed, and its ability to consider the total variance of measurement items while testing the model (Hair et al., 2012; Hair et al., 2017). In this study, the objective is to predict relationships between the constructs of interest rather than confirming a theory. Also, the prediction orientation of PLS-PM makes it an ideal technique for determining the factors influencing CEB. Following Hair et al., (2017), the model was analysed and interpreted in two stages: examining the validity and reliability of the measurement model followed by empirical testing of the proposed hypotheses.

\subsection{Common Method Bias (CMB)}

The collection of data from the single source allowed CMB to possibly affect the relationships between the constructs (Podsakoff et al., 2003). In this study, the CMB was controlled using both procedural and statistical methods. Several procedural remedies were adopted in the study design phase. These include ensured the anonymity of the participants, informed participants that there are no correct or incorrect answers, requested them to respond to the questionnaire as honestly as possible, used different scale formats (Likert scale and semantic differential scale), and improvised the wording of measurement item during the pilot study (Podsakoff et al., 2003). Statistically, Harman's single-factor test was performed, and it was found that no single factor exceeds the threshold of more than $50 \%$ of the total variance (Podsakoff et al., 2003). Moreover, an examination of the model constructs' correlation matrix showed 0.601 being the highest correlation value, thus remaining well below the critical threshold limit of 0.90 (Pavlou et al., 2006). The marker variable approach recommended by Lindell and Whitney (2001) and Tehseen et al. (2017) was also used. We used respondents' mobile phone usage intensity as an unrelated construct. Mobile phone usage intensity refers to the extent to which mobile phones are integrated into the daily routines of the respondents. We adapted the items from Valenzuela et al. (2009) to measure the market variable, i.e., mobile phone usage intensity. The inclusion of the marker variable did not significantly increase the variance of the dependent variable. Results indicate that the average correlation between latent variables in the proposed research model and the marker variable is 0.035 , and the average significance was 0.53 , which is well above the threshold of 0.05 and makes it necessary to 
consider the correlations as being significant. Therefore, common method bias is not a major issue in this study.

\subsection{Measurement properties}

Table 1 shows the measurement model and the psychometric properties of the scale. The constructs' reliability, convergent validity, and discriminant validity were examined. The results highlighted that the standardised factor loadings are well above the recommended minimum threshold levels of 0.50 (Hair et al., 2006). The reliability of the variables as indicated by Cronbach's alpha and composite reliability is greater than the recommended threshold levels of .70 and .80, respectively (Hair et al., 2006). Results highlight that the measurement model has adequate internal consistency. Also, the average variance extracted for each construct surpassed the threshold levels of 0.50 (Hair et al., 2006). This value supported the convergent validity of the measurement model. The discriminant validity of the measurement model was examined using two methods, namely, Fornell and Larcker (1981) method and the HTMT-ratio approach. The former method proposes the discriminant validity of the construct to be satisfactory if the square root of the average variance extracted of each construct was greater than the correlations it shared with other constructs (Fornell and Larcker, 1981). It was found satisfactory in the measurement model. With HTMT ratio values less than 0.90 (Henseler et al., 2015), the model also indicated satisfactory discriminant validity. We also computed the variance inflation factor (VIF) to check for the multicollinearity among the constructs in the proposed research model. Results show that the full VIF value was 2.56. Hence, there is no concern around multicollinearity (Petter et al., 2007). Since the full VIF value was less than the cut-off threshold value of 3.3, multicollinearity is not an issue in this study (Kock, 2015).

\subsection{Structural model results}

Following the measurement model, the structural model was evaluated. We employed the Rsquared coefficient to assess the fit of the structural model. The explanatory power of the model was assessed using the measure of explained variance. The $\mathrm{R}^{2}$ value of performance expectancy $(17 \%)$, effort expectancy $(15 \%)$, social influence $(12 \%)$, and facilitating conditions $(14 \%)$ indicated medium effect size ( . 09, Cohen, 1988). The $\mathrm{R}^{2}$ value of attitude $(40 \%)$ and CEB (46\%) indicated large effect sizes ( .25, Cohen, 1988). Considering the exploratory nature of the study, we contend that $\mathrm{R}^{2}$ values highlight a good representation of the data to the measurement and structural model (Hair et al., 2012). The Stone-Geisser Q2 values for all the endogenous constructs in this study are positive, highlighting the predictive validity of the research model (Chin and Newsted, 1999; Hair et al., 2012). Further, the goodness-of-fit (GoF) is defined "as the geometric mean of the average commonality, and the average $\mathrm{R}^{2}$ " (Tenenhaus et al., 2005, p. 173) for the complete structural model was 0.41 which confirms that the model performs well.

Table 2 presents the path coefficients along with t-statistics. The PLS structural equation modelling results support several of the proposed hypotheses. The hypothesis $\mathrm{H} 1-\mathrm{H} 3$ predicted the impact of SRT characteristics on affective responses measured by the UTAUT variables. H1 (a-d), which suggested there was a positive relationship between SRT novelty and UTAUT variables was partially supported. 


\begin{tabular}{|c|c|c|c|c|c|}
\hline \multirow[t]{2}{*}{ Constructs and Items } & \multicolumn{5}{|c|}{ Measurement Properties } \\
\hline & Loadings & $\begin{array}{l}\mathrm{T} \\
\text { Statistics }\end{array}$ & $\begin{array}{l}\text { Cronbach's } \\
\text { Alpha }\end{array}$ & $\begin{array}{l}\text { Composite } \\
\text { Reliability }\end{array}$ & $\begin{array}{l}\text { Average Variance } \\
\text { Extracted (AVE) }\end{array}$ \\
\hline Performance Expectancy (PEX) & & & 0.925 & 0.947 & 0.816 \\
\hline PEX1 & 0.884 & 47.353 & & & \\
\hline PEX2 & 0.92 & 56.984 & & & \\
\hline PEX3 & 0.926 & 76.814 & & & \\
\hline PEX4 & 0.882 & 50.772 & & & \\
\hline Effort Expectancy (EEX) & & & 0.888 & 0.923 & 0.752 \\
\hline EEX1 & 0.884 & 44.772 & & & \\
\hline EEX2 & 0.896 & 51.37 & & & \\
\hline EEX3 & 0.905 & 57.704 & & & \\
\hline EEX4 & 0.776 & 25.471 & & & \\
\hline Social Influence (SIF) & & & 0.892 & 0.916 & 0.609 \\
\hline SIF1 & 0.783 & 23.617 & & & \\
\hline SIF2 & 0.808 & 24.37 & & & \\
\hline SIF3 & 0.729 & 21.152 & & & \\
\hline SIF4 & 0.793 & 26.201 & & & \\
\hline SIF5 & 0.852 & 34.501 & & & \\
\hline SIF6 & 0.834 & 29.363 & & & \\
\hline SIF7 & 0.646 & 12.968 & & & \\
\hline Facilitating Conditions (FCD) & & & 0.858 & 0.903 & 0.7 \\
\hline FCD1 & 0.849 & 35.336 & & & \\
\hline FCD2 & 0.861 & 34.24 & & & \\
\hline FCD3 & 0.824 & 26.399 & & & \\
\hline FCD4 & 0.811 & 24.884 & & & \\
\hline SRT Novelty (Novel) & & & 0.921 & 0.943 & 0.804 \\
\hline Novel1 & 0.848 & 25.564 & & & \\
\hline Novel2 & 0.913 & 73.385 & & & \\
\hline Novel3 & 0.916 & 66.338 & & & \\
\hline Novel4 & 0.909 & 56.802 & & & \\
\hline SRT Effectiveness (SEF) & & & 0.815 & 0.872 & 0.63 \\
\hline SEF1 & 0.739 & 15.429 & & & \\
\hline SEF2 & 0.822 & 17.171 & & & \\
\hline SEF3 & 0.84 & 21.404 & & & \\
\hline SEF4 & 0.771 & 15.437 & & & \\
\hline SRT Interaction Quality (INQ) & & & 0.834 & 0.923 & 0.858 \\
\hline INQ1 & 0.927 & 62.455 & & & \\
\hline INQ2 & 0.925 & 49.6 & & & \\
\hline Attitude towards SRT (ATT) & & & 0.939 & 0.961 & 0.891 \\
\hline ATT1 & 0.942 & 85.473 & & & \\
\hline ATT2 & 0.947 & 110.216 & & & \\
\hline ATT3 & 0.942 & 94.324 & & & \\
\hline $\begin{array}{l}\text { Behavioural intentions towards } \\
\text { SRT (BIN) }\end{array}$ & & & 0.937 & 0.955 & 0.841 \\
\hline BIN1 & 0.92 & 81.925 & & & \\
\hline BIN2 & 0.916 & 78.302 & & & \\
\hline BIN3 & 0.907 & 63.397 & & & \\
\hline BIN4 & 0.924 & 87.8 & & & \\
\hline $\begin{array}{l}\text { Customer Engagement Behaviour } \\
\text { (CEB) }\end{array}$ & & & 0.85 & 0.9 & 0.701 \\
\hline CEB1 & 0.888 & 57.783 & & & \\
\hline CEB2 & 0.928 & 60.312 & & & \\
\hline CEB3 & 0.934 & 91.221 & & & \\
\hline CEB4 & 0.531 & 7.474 & & & \\
\hline
\end{tabular}

Table 1. Measurement model and psychometric properties of the scale 
Specifically, SRT novelty was found to positively influence performance expectancy, thereby supporting H1a $(\beta=0.121, p<0.05)$, however, H1b $(\beta=0.009, p=0.888), H 1 c(\beta=0.291, p=0.077)$, H1d $(\beta=0.038, p=0.51)$ are not supported as SRT novelty did not impact effort expectancy, social influence and facilitating conditions. $\mathrm{H} 2(\mathrm{a}-\mathrm{d})$, which anticipated a positive relationship between SRT effectiveness and UTAUT variables, was partially supported. Specifically, support was found for the suggested positive relationship between SRT effectiveness and performance expectancy, effort expectancy and facilitating conditions, thereby supporting $\mathrm{H} 2 \mathrm{a}(\beta=0.122, \mathrm{p}<0.01), \mathrm{H} 2 \mathrm{~b}(\beta=0.328, \mathrm{p}<0.01), \mathrm{H} 2 \mathrm{~d}(\beta=0.342, \mathrm{p}<0.01)$, however, H2c $(\beta=0.059$, $\mathrm{p}=0.316)$ is rejected as SRT effectiveness did not support social influence. H3 (a-d), which suggested a positive relationship between SRT interaction quality and UTAUT variables was partially supported. Precisely, support was found for the suggested positive relationship between SRT interaction quality and performance expectancy, effort expectancy and facilitating conditions, thereby supporting H3a $(\beta=0.279, \mathrm{p}<0.01), \mathrm{H} 3 \mathrm{~b}(\beta=0.183, \mathrm{p}<0.01), \mathrm{H} 3 \mathrm{~d}$ $(\beta=0.151, p<0.05)$ however, H3c $(\beta=0.125, p=0.07)$ is rejected as SRT interaction quality did not support social influence. Performance expectancy $(\beta=0.385, p<0.01)$, social influence $(\beta=$ $0.165, \mathrm{p}<0.01)$, and facilitating conditions $(\beta=0.122, \mathrm{p}<0.01)$, are shown to positively affect online customers' attitude towards SRT, so $\mathrm{H} 4 \mathrm{a}, \mathrm{H} 4 \mathrm{c}$, and $\mathrm{H} 4 \mathrm{~d}$ are supported. However, $\mathrm{H} 4 \mathrm{~b}$ is not supported since effort expectancy $(\beta=0.138, \mathrm{p}=0.112)$ did not impact customers' attitudes towards SRT. The direct effect of attitude towards SRT on CEB is significant and positive ( $\beta=$ $0.254, \mathrm{p}<0.001)$, which provides support to hypothesis H5.

\subsection{Mediation analysis}

In this study, $\mathrm{H} 6$ and $\mathrm{H} 7$ proposed that attitude and behavioural intention plays key mediating roles in the proposed research model. We investigated the mediating effects by testing the indirect effects and bias-corrected bootstrap confidence intervals (Hair et al., 2017; Nitzl et al., 2016), and results are shown in Table 2. Results also show that the indirect effects between performance expectancy and CEB $(\beta=0.226, p<0.001)$ and between social influence and CEB $(\beta=0.077, p<0.01)$ are significant the bias-corrected bootstrap confidence intervals are different from zero (as shown in Table 2). The direct effect of performance expectancy on CEB is significant. Hence, attitude is a complementary mediator between performance expectancy and CEB. The direct effect of social influence on CEB is not significant. Thus, attitude is an indirect only mediator between social influence and CEB (Zhao et al., 2010). The indirect effects of effort expectancy and CEB and facilitating conditions are not significant. Hence, results show partial support for hypothesis H6. Results also show that the indirect effect of attitude towards SRT on CEB is significant $(\beta=0.125, p<0.01)$. The bias-corrected bootstrap confidence interval of behavioural intention as a mediator between attitude and CEB is different from zero ( 0.049 to 0.209$)$. The direct effect of attitude on CEB is significant $(\beta=0.254, p<0.001)$. Thus, we conclude that behavioural intention acts as a complementary mediator (Zhao et al., 2010). Therefore hypothesis H7 is supported in this study.

\section{Discussion and implications}

The findings of this study offer several key insights associated with examining factors influencing CEB towards SRT. Using PLS-PM, this research focuses on examining the role of SRT characteristics in shaping customers' affective response towards SRT, which eventually impacts customers' attitude, intention, and CEB towards SRT. More specifically, this study shows how SRT novelty, SRT effectiveness, and SRT interaction quality impacts customers' perceptions about TA (performance expectancy, effort expectancy), and, CF (social influence 
and facilitating conditions). Findings also show how TA and CF shape customers' attitude towards SRT and ultimately impacts CEB towards SRT. Finally, we investigate the mediating role of behavioural intention in the relationship between attitude- and CEB towards SRT.

\begin{tabular}{|c|c|c|c|c|c|}
\hline Hypothesis & Relationships & $\begin{array}{l}\text { Path } \\
\text { coefficients }\end{array}$ & $\begin{array}{l}\mathrm{T}- \\
\text { value }\end{array}$ & $\begin{array}{l}\mathrm{P} \text { - } \\
\text { value }\end{array}$ & Inference \\
\hline \multicolumn{6}{|c|}{ Control Relationships } \\
\hline & Age $\rightarrow$ CEB_SRT & 0.068 & 1.649 & 0.106 & $\begin{array}{l}\text { Not } \\
\text { Significant }\end{array}$ \\
\hline & Gender $\rightarrow$ CEB_SRT & 0.044 & 1.035 & 0.313 & $\begin{array}{l}\text { Not } \\
\text { Significant }\end{array}$ \\
\hline \multicolumn{6}{|c|}{ Model Relationships } \\
\hline H1 (a) & SRT_Novelty $\rightarrow$ Performance_Expectancy & 0.121 & 2.023 & $<.05^{*}$ & Significant \\
\hline H1 (b) & SRT_Novelty $\rightarrow$ Effort_Expectancy & 0.009 & 0.141 & 0.888 & $\begin{array}{l}\text { Not } \\
\text { Significant }\end{array}$ \\
\hline H1 (c) & SRT_Novelty $\rightarrow$ Social_Influence & 0.291 & 1.766 & 0.077 & $\begin{array}{l}\text { Not } \\
\text { Significant }\end{array}$ \\
\hline $\mathrm{H} 1 \mathrm{(d)}$ & SRT_Novelty $\rightarrow$ Facilitating_Conditions & 0.038 & 0.659 & 0.51 & $\begin{array}{l}\text { Not } \\
\text { Significant }\end{array}$ \\
\hline $\mathrm{H} 2$ (a) & SRT_Effectiveness $\rightarrow$ Performance_Expectancy & 0.227 & 4.012 & $<.01^{* *}$ & Significant \\
\hline $\mathrm{H} 2(\mathrm{~b})$ & SRT_Effectiveness $\rightarrow$ Effort_Expectancy & 0.328 & 5.716 & $<.01^{* *}$ & Significant \\
\hline $\mathrm{H} 2$ (c) & SRT_Effectiveness $\rightarrow$ Social_Influence & 0.059 & 1.003 & 0.316 & $\begin{array}{l}\text { Not } \\
\text { Significant }\end{array}$ \\
\hline $\mathrm{H} 2(\mathrm{~d})$ & SRT_Effectiveness $\rightarrow$ Facilitating_Conditions & 0.342 & 5.942 & $<.01^{* *}$ & Significant \\
\hline H3 (a) & $\begin{array}{l}\text { SRT_Interaction_Quality } \rightarrow \\
\text { Performance_Expectancy }\end{array}$ & 0.279 & 3.8 & $<.01^{* *}$ & Significant \\
\hline $\mathrm{H} 3(\mathrm{~b})$ & SRT_Interaction_Quality $\rightarrow$ Effort_Expectancy & 0.183 & 2.537 & $<.05^{*}$ & Significant \\
\hline H3 (c) & SRT_Interaction_Quality $\rightarrow$ Social_Influence & 0.125 & 1.766 & 0.077 & $\begin{array}{l}\text { Not } \\
\text { Significant }\end{array}$ \\
\hline H3 (d) & $\begin{array}{l}\text { SRT_Interaction_Quality } \rightarrow \\
\text { Facilitating_Conditions }\end{array}$ & 0.151 & 2.161 & $<.05^{*}$ & Significant \\
\hline $\mathrm{H} 4$ (a) & Performance_Expectancy $\rightarrow$ Attitude_SRT & 0.385 & 4.856 & $<.01^{* *}$ & Significant \\
\hline H4 (b) & Effort_Expectancy $\rightarrow$ Attitude_SRT & 0.138 & 1.591 & 0.112 & $\begin{array}{l}\text { Not } \\
\text { Significant }\end{array}$ \\
\hline $\mathrm{H} 4$ (c) & Social_Influence $\rightarrow$ Attitude_SRT & 0.165 & 3.147 & $<.01^{* *}$ & Significant \\
\hline $\mathrm{H} 4(\mathrm{~d})$ & Facilitating_Conditions $\rightarrow$ Attitude_SRT & 0.122 & 2.28 & $<.05^{*}$ & Significant \\
\hline H5 & Attitude_SRT $\rightarrow$ CEB & 0.254 & & $\begin{array}{l}< \\
0.001^{* * *}\end{array}$ & Significant \\
\hline
\end{tabular}

\begin{tabular}{|c|c|c|c|c|c|c|c|}
\hline \multicolumn{8}{|c|}{ Mediation Relationships } \\
\hline & & $\begin{array}{c}\text { Indirect } \\
\text { Effect }\end{array}$ & $\begin{array}{c}\text { T- } \\
\text { Values }\end{array}$ & $\begin{array}{l}\mathrm{P} \\
\text { Values }\end{array}$ & $\begin{array}{l}\mathrm{LCL} \\
(\mathbf{2 . 5 \%})\end{array}$ & $\begin{array}{c}\text { UCL } \\
(97.5 \%)\end{array}$ & Inference \\
\hline \multirow{4}{*}{ H6 } & $\begin{array}{l}\text { Performance_Expectancy } \rightarrow \\
\text { Attitude_SRT } \rightarrow \text { CEB }\end{array}$ & 0.226 & 3.746 & 0 & 0.115 & 0.35 & Significant \\
\hline & $\begin{array}{l}\text { Effort_Expectancy } \\
\text { Attitude_SRT } \rightarrow \text { CEB }\end{array}$ & 0.089 & 1.622 & 0.097 & -0.017 & 0.192 & $\begin{array}{l}\text { Not } \\
\text { Significant }\end{array}$ \\
\hline & $\begin{array}{l}\text { Social_Influence } \rightarrow \\
\text { Attitude_SRT } \rightarrow \text { CEB }\end{array}$ & 0.077 & 1.981 & 0.04 & 0.002 & 0.152 & Significant \\
\hline & $\begin{array}{l}\text { Facilitating_Conditions } \\
\text { Attitude_SRT } \rightarrow \text { CEB }\end{array}$ & 0.15 & 0 & 0.05 & -0.001 & 0.184 & $\begin{array}{l}\text { Not } \\
\text { Significant }\end{array}$ \\
\hline $\mathrm{H} 7$ & $\begin{array}{l}\text { Attitude_SRT } \rightarrow \text { Behavioural } \\
\text { Intention } \rightarrow \text { CEB }\end{array}$ & 0.125 & 3.059 & 0.002 & 0.049 & 0.209 & Significant \\
\hline
\end{tabular}

Table 2. Structural model results 


\subsection{Theoretical contributions}

The findings of this study adds to the contemporary marketing and IS literature. Specifically, findings contribute to the ongoing debate about evolving customer engagement and associated behaviours due to the rapid infusion of futuristic in-store retail technologies (Grewal et al., 2020). Prior research has explored SRT (Huang and Liao, 2015; Müller-Seitz et al., 2009) and provided understandings regarding the factors that influence customer adoption of these SRT (Adapa et al., 2020; Roy et al., 2018a). However, to our knowledge, there is no thorough examination of factors driving CEB towards SRT (Fan et al., 2020). This study is one of the first to examine whether and how technology attributes and contextual factors derived from meta-UTAUT (Dwivedi et al., 2019) influence customers' attitudes towards SRT and eventually impacts CEB towards SRT. Results contribute to the literature in several ways.

First, the study empirically validates the theoretical conceptualisation of meta-UTAUT (Dwivedi et al., 2019) in the IS literature. In doing so, researchers propose that (a) attitude directly impacts usage behaviour (b) attitude mediates the effects of TA (performance expectancy and effort expectancy), and CF (facilitating conditions and social influence) on user behaviour. The PLS-PM results validate that customers' attitudes towards SRT directly influenced CEB towards SRT and also mediated the effects of TA, CF on CEB. By doing so, the study deviates from the widely prevalent theoretical conceptualisation in the literature that does not include the role of customer attitude in shaping usage behaviour and instead relies on directly monitoring the impact of TA, CF on behavioural intention and engagement behaviour (Alalwan et al., 2017; Kapser and Abdelrahman, 2020).

Secondly, previous studies have examined the role of customer engagement (cognitive and emotional) in establishing CEB towards SRT (Fan et al., 2020). Since, attitude plays a central role in the usage behaviour of technologically innovative products (Dwivedi et al., 2019, 2020), the present study incorporated and investigated the role of customers' attitude and behavioural intention in displaying CEB towards SRT. This contribution is a welcome addition to the literature given the lack of research into CEB towards SRT (Wang, 2020).

Third, the results advance earlier research on factors influencing customers' attitude towards SRT. The findings of this study extend the antecedents of customers attitude towards SRT by incorporating the role of TA and CF in influencing customers' attitudes towards SRT. This study answers the call for more research into including the contextual factors in technologyenabled retail environments (Patil et al., 2020; Hollebeek et al., 2019). Results reveal effort expectancy to be a non-significant predictor of customers' attitude towards SRT. This result can be interpreted with an argument that effort expectancy may not act as a strong predictor if facilitating conditions are included in the model (Venkatesh et al., 2003). These findings extend our knowledge concerning the role of additional antecedents influencing customers' attitudes towards SRT.

Finally, regarding SRT characteristics, results support the role of SRT novelty, SRT effectiveness, and SRT interaction quality in influencing customers' performance expectancy. The results also support the role of SRT effectiveness and SRT interaction quality in influencing customers' perception of effort expectancy and facilitating conditions. These findings corroborate and enhance previous research findings on the role of SRT characteristics in enhancing perceived value (Adapa et al., 2020). Overall, by examining the impact of SRT characteristics on customers' affective responses and its subsequent impact in driving 
customers' attitude, behavioural intention, and CEB extend our understanding of factors that influence CEB towards SRT.

\subsection{Managerial implications}

Our findings show that customers' attitude towards SRT significantly influenced CEB towards SRT, which implies smart retailers may find it beneficial to shape customers' attitudes towards SRT for eventually encouraging them to display CEB. Our results reveal that customers' attitude towards SRT is shaped by one of the technology attributes (i.e., performance expectancy) (Weerakkody et al., 2017). This result signifies customers put significant importance to the fact of whether technology in question offers a significant gain in their shopping task. Therefore, retailers should concentrate on selecting those SRT that can lower shopping hassle, and discomfort, and also can efficiently meet customer needs. Possible ways to accomplish these objectives may include ensuring the increased coordination with the developers/testers of SRT to synchronise the performance of SRT with customer expectations (Roy et al., 2018a). In addition to that, retailers may execute strategies to communicate SRT capabilities to potential customers through product brochures, live demonstrations, and success stories (e.g., Martin and Herrero 2012; Zuiderwijk et al., 2015). The results also signify that customers' attitudes towards SRT are also shaped by the contextual factors (i.e., facilitating conditions and social influence). Interpreting further reveals customers attribute high importance to facilitating conditions such as intelligent systems linked with SRT and as well as to the experiences of other individuals in using the technology. Hence, retailers should consider offering high-grade infrastructural facilities such as virtual shelves, interactive screens, and in-store mobile apps (Fan et al., 2020). Also, assistance/training centres in the premises may act as one of the important drivers to encourage customers' attitudes towards SRT (Sabherwal et al., 2006; Chiu et al., 2012). Smart retailers may proactively engage in creating social influence with a capacity of exerting influence on customers. This engagement may include arranging forums/panels for exchanging best use practices or instituting advocates who are inspired to use SRT which eventually can generate positive word-of-mouth, and handle negative feedback (Pynoo et al., 2011).

Our results reveal that the technology characteristics influence customers' perception of technology attributes (performance expectancy and effort expectancy) and contextual factors (social influence and facilitating conditions). In the context of SRT, performance expectancy is influenced by all three SRT characteristics examined in the study (i.e. novelty, effectiveness, and interaction quality). Also, effort expectancy and facilitating conditions are influenced by effectiveness and interaction quality. Hence, retailers should consider adopting those SRT that have a novel stimulus, quality interaction, and are effective.

\subsection{Limitations and future research directions}

\subsubsection{Limitations}

Despite its vital contributions to literature, the study has several limitations. First, while several proposed hypotheses are supported, the study reveals the low explanatory power of the structural model. The low explanatory power may be attributed to the wide variety of SRT examined in the research model. Secondly, the present study used only the meta-UTAUT (Dwivedi et al., 2019) as an overarching framework to understand CEB towards smart retailing. Third, the present study used a cross-sectional design. The present study examines the determinants of CEB towards SRT by adopting a unidimensional view of CEB. 
Furthermore, the present study controlled for the effects of customer demographics in understanding CEB towards smart retailing.

\subsubsection{Future research directions}

This research sets the direction for researchers to explore the scope to accommodate other significant psychological constructs, i.e. motivation. Future studies may use alternate behavioural theories such as Behavioural reasoning theory (BRT) (Westaby, 2005; Claudy et al., 2015) since BRT based models are known for high prediction powers in terms of the variance explained in the dependent variables (Sahu et al., 2020). As SRT may differ in terms of characteristics (Wünderlich et al., 2015), future research should, therefore, consider the research model for specific SRT such as smart displays, smart shopping carts, or NFC-based systems and evaluate how differently it influences behavioural outcomes. Future studies can adopt a longitudinal design for a more insightful understanding of the CEB (Bijmolt et al., 2010). The present study examines the determinants of CEB towards SRT by adopting a unidimensional view of CEB. The multidimensional conceptualisation of CEB (Roy et al., 2018b; Jaakkola and Alexander, 2014) can add to the existing insights. Since the age group and gender may influence CEB towards technology, future research could examine their role in CEB for SRT.

\section{Conclusion}

The analysis of customer attitude and behaviour towards SRT considering the SRT characteristics and the given context of customer affective responses captures the backdrop of CEB toward SRT. The results highlight the mediating role of attitude and behavioural intention towards SRT to enhance CEB. The noteworthy findings emerging from this research demonstrates that CEB towards SRT can be achieved via carefully considering SRT characteristics such as novelty, effectiveness and interaction quality. Given the importance of engaging customers, for managers of smart retailing, this study specifies the significance of services characteristics to influence customers' affective responses positively.

\section{References}

Adapa, S., Fazal-e-Hasan, S. M., Makam, S. B., Azeem, M. M., \& Mortimer, G. (2020). Examining the antecedents and consequences of perceived shopping value through smart retail technology. Journal of Retailing and Consumer Services, 52, 101901.

Adams, J. S. (1963). Wage inequities, productivity and work quality. Industrial Relations: A Journal of Economy and Society, 3(1), 9-16.

Ajzen, I. (1991). The theory of planned behaviour. Organisational Behaviour and Human Decision Processes, 50(2), 179-211.

Ajzen, I. (2011) The theory of planned behaviour: Reactions and reflections, Psychology \& Health, 26:9, 1113-1127.

Alalwan, A. A., Dwivedi, Y. K., \& Rana, N. P. (2017). Factors influencing adoption of mobile banking by Jordanian bank customers: Extending UTAUT2 with trust. International Journal of Information Management, 37(3), 99-110.

Ángeles Oviedo-García, M., Muñoz-Expósito, M., Castellanos-Verdugo, M. and SanchoMejías, M. (2014), "Metric proposal for customer engagement in Facebook", Journal of Research in Interactive Marketing, 8(4), 327-344. 
Attié, E., Meyer-Waarden, L., \& Bachié, E. (2020). Consumer Acceptance and Resistance Factors Toward Smart Retail Stores. In Chkoniya, V., Madsen, A. O., \& Bukhrashvili, P. (Ed.), Anthropological Approaches to Understanding Consumption Patterns and Consumer Behaviour (pp. 119-136). IGI Global. http://doi:10.4018/978-1-7998-31150.ch007

Australian Retailers Association (2020), Retail technology trends shaping customer experience in 2020, https://blog.retail.org.au/newsandinsights/retail-technology-trends-shapingcustomer-experience-in-2020

Bagozzi, R. P., \& Yi, Y. (1989). The degree of intention formation as a moderator of the attitudebehaviour relationship. Social psychology quarterly, 266-279.

Baishya, K., \& Samalia, H. V. (2020). Extending unified theory of acceptance and use of technology with perceived monetary value for smartphone adoption at the bottom of the pyramid. International Journal of Information Management, 51(10); 20-36.

Bapna, R., \& Umyarov, A. (2015). Do your online friends make you pay? A randomised field experiment on peer influence in online social networks. Management Science, 61(8),1902-1920.

Balaji, M. S. (2014). Managing customer citizenship behaviour: A relationship perspective. Journal of Strategic Marketing, 22(3), 222-239.

Balaji, M. S., \& Roy, S. K. (2017). Value co-creation with Internet of things technology in the retail industry. Journal of Marketing Management, 33(1-2), 7-31.

Baldus, B. J., Voorhees, C., \& Calantone, R. (2015). Online brand community engagement: Scale development and validation. Journal of Business Research, 68(5), 978-985.

Bejerholm, U., \& Eklund, M. (2007). Occupational engagement in persons with schizophrenia: Relationships to self-related variables, psychopathology, and quality of life. American Journal of Occupational Therapy, 61(1), 21-32.

Bhattacherjee, A., \& Sanford, C. (2009). The intention-behaviour gap in technology usage: the moderating role of attitude strength. Behaviour \& Information Technology, 28(4), 389401.

Bijmolt, T. H., Leeflang, P. S., Block, F., Eisenbeiss, M., Hardie, B. G., Lemmens, A., \& Saffert, P. (2010). Analytics for customer engagement. Journal of Service Research, 13(3), 341356.

Blythe, J. (1999), Innovativeness and newness in high-tech consumer durables, Journal of Product \& Brand Management, 8(5), 415-429.

Book, L. A., Tanford, S., Montgomery, R., \& Love, C. (2018). Online traveler reviews as social influence: Price is no longer king. Journal of Hospitality \& Tourism Research, 42(3), 445475 .

Brown, S. A., \& Venkatesh, V. (2005). Model of adoption of technology in households: A baseline model test and extension incorporating household life cycle. MIS Quarterly, 29(3), 399-426.

Brady, M. K., \& Cronin Jr, J. J. (2001). Some new thoughts on conceptualising perceived service quality: a hierarchical approach. Journal of Marketing, 65(3), 34-49. 
Brodie, R. J., Hollebeek, L. D., Jurić, B., \& Ilić, A. (2011). Customer engagement: Conceptual domain, fundamental propositions, and implications for research. Journal of Service Research, 14(3), 252-271.

Carter, S., \& Yeo, A. C. M. (2016). Mobile apps usage by Malaysian business undergraduates and postgraduates. Internet Research, 26 (3), 733-757.

Caro, F., \& Sadr, R. (2019). The Internet of Things (IoT) in retail: Bridging supply and demand. Business Horizons, 62(1), 47-54.

Chin, W. W., \& Newsted, P. R. (1999). Structural equation modeling analysis with small samples using partial least squares. Statistical strategies for small sample research, 1(1), 307-341.

Chiu, H. C., Hsieh, Y. C., Roan, J., Tseng, K. J., \& Hsieh, J. K. (2011). The challenge for multichannel services: Cross-channel free-riding behaviour. Electronic Commerce Research and Applications, 10(2), 268-277.

Chiu, Y. T. H., Lee, W. I., Liu, C. C., \& Liu, L. Y. (2012). Internet lottery commerce: An integrated view of online sport lottery adoption. Journal of Internet Commerce, 11(1), 68-80.

Chong, A. Y. L. (2013). Predicting m-commerce adoption determinants: A neural network approach. Expert Systems with Applications, 40 (2), 523-530.

Claudy, M. C., Garcia, R., \& O'Driscoll, A. (2015). Consumer resistance to innovation-a behavioural reasoning perspective. Journal of the Academy of Marketing Science, 43(4), 528-544.

Collier, J. E., Moore, R. S., Horky, A., \& Moore, M. L. (2015). Why the little things matter: Exploring situational influences on customers' self-service technology decisions. Journal of Business Research, 68(3), 703-710.

Cohen, S. (1988). Psychosocial models of the role of social support in the etiology of physical disease. Health psychology, 7(3), 269.

Davis, F. D. (1989). Perceived usefulness, perceived ease of use, and user acceptance of information technology. MIS Quarterly, 13(3), 318-339.

De Keyser, A., Verleye, K., Lemon, K. N., Keiningham, T. L., \& Klaus, P. (2020). Moving the Customer Experience Field Forward: Introducing the Touchpoints, Context, Qualities (TCQ) Nomenclature. Journal of Service Research, doi.org/10.1177/1094670520928390

Dwivedi, Y. K., Rana, N. P., Tamilmani, K., \& Raman, R. (2020). A meta-analysis based modified unified theory of acceptance and use of technology (Meta-UTAUT): A review of emerging literature. Current Opinion in Psychology, 36, 13-18.

Dwivedi, Y. K., Rana, N. P., Jeyaraj, A., Clement, M., \& Williams, M. D. (2019). Re-examining the unified theory of acceptance and use of technology (UTAUT): Towards a revised theoretical model. Information Systems Frontiers, 21(3), 719-734.

Elek, E., Miller-Day, M., \& Hecht, M. L. (2006). Influences of personal, injunctive, and descriptive norms on early adolescent substance use. Journal of Drug Issues, 36(1), 147172. 
Evanschitzky, H., Iyer, G. R., Pillai, K. G., Kenning, P., \& Schütte, R. (2015). Consumer trial, continuous use, and economic benefits of a retail service innovation: The case of the personal shopping assistant. Journal of Product Innovation Management, 32(3), 459-475.

Fan, X., Ning, N., \& Deng, N. (2020). The impact of the quality of intelligent experience on smart retail engagement. Marketing Intelligence \& Planning, (forthcoming).

Ferracuti, N., Norscini, C., Frontoni, E., Gabellini, P., Paolanti, M., \& Placidi, V. (2019). A business application of RTLS technology in Intelligent Retail Environment: Defining the shopper's preferred path and its segmentation. Journal of Retailing and Consumer Services, 47, 184-194.

Fishbein, M., \& Ajzen, I. (1975). Belief, attitude, intention, and behaviour: An introduction to theory and research. Reading: Addison-Wesley Publication Company.

Fornell, C., \& Larcker, D. F. (1981). Evaluating structural equation models with unobservable variables and measurement error. Journal of Marketing Research, 18(1), 39-50.

Foroudi, P., Gupta, S., Sivarajah, U., \& Broderick, A. (2018). Investigating the effects of smart technology on customer dynamics and customer experience. Computers in Human Behaviour, 80, 271-282.

Graf-Vlachy, L., Buhtz, K., \& König, A. (2018). Social influence in technology adoption: taking stock and moving forward. Management Review Quarterly, 68(1), 37-76.

Gregory, J., (2016). The Internet of things: Revolutionising the retail industry. Accenture Strategy. Retrieved from 〈https://www.accenture.com/gb-en/insight-internet-

Grewal, D., \& Roggeveen, A. L. (2020). Understanding retail experiences and customer journey management. Journal of Retailing, 96(1), 3-8.

Grewal, D., Noble, S. M., Roggeveen, A. L., \& Nordfalt, J. (2020a). The future of in-store technology. Journal of the Academy of Marketing Science, 48(1), 96-113.

Grewal, D., Hulland, J., Kopalle, P.K. (2020b) The future of technology and marketing: a multidisciplinary perspective. Journal of the Academy of Marketing Science. 48, 1-8 (https://doi.org/10.1007/s11747-019-00711-4

Grewal, D., Ahlbom, C. P., Beitelspacher, L., Noble, S. M., \& Nordfält, J. (2018). In-store mobile phone use and customer shopping behaviour: Evidence from the field. Journal of Marketing, 82 (4), 102-126.

Hair Jr, J. F., Sarstedt, M., Ringle, C. M., \& Gudergan, S. P. (2017). Advanced issues in partial least squares structural equation modeling. Sage publications.

Hair, J. F., Black, W. C., Babin, B. J., Anderson, R. E., \& Tatham, R. L. (2006). Multivariate data analysis (Vol. 6).

Hair, J. F., Sarstedt, M., Ringle, C. M., \& Mena, J. A. (2012). An assessment of the use of partial least squares structural equation modeling in marketing research. Journal of the Academy of Marketing Science, 40(3), 414-433.

Henseler, J., Ringle, C. M., \& Sarstedt, M. (2015). A new criterion for assessing discriminant validity in variance-based structural equation modeling. Journal of the Academy of Marketing Science, 43(1), 115-135. 
Hollebeek, L. D., Conduit, J., \& Brodie, R. J. (2016). Strategic drivers anticipated and unanticipated outcomes of customer engagement, Journal of Marketing Management, 32 (5-6), 393-398.

Hollebeek, L.D., Sprott, D.E., Andreassen, T.W., Costley, C., Klaus, P., Kuppelwieser, V., Karahasanovic, A., Taguchi, T., Ul Islam, J. and Rather, R.A. (2019). Customer engagement in evolving technological environments: synopsis and guiding propositions. European Journal of Marketing, 53 (9), 2018-2023.

Hossain, M. A., Hasan, M. I., Chan, C., \& Ahmed, J. U. (2017). Predicting user acceptance and continuance behaviour towards location-based services: the moderating effect of facilitating conditions on behavioural intention and actual use. Australasian Journal of Information Systems, 21, 1-22.

Huang, T. L., \& Liao, S. (2015). A model of acceptance of augmented-reality interactive technology: the moderating role of cognitive innovativeness. Electronic Commerce Research, 15(2), 269-295.

IBIS World (2018), Retail Trade in Australia, https://www.ibisworld.com/au/retail-sector/

Inman, J. J., \& Nikolova, H. (2017). Shopper-facing retail technology: A retailer adoption decision framework incorporating shopper attitudes and privacy concerns. Journal of Retailing, 93(1), 7-28.

Islam, J.U. and Rahman, Z. (2016), "The transpiring journey of customer engagement research in marketing: A systematic review of the past decade", Management Decision, 54 (8), 2008-2034.

Iyengar, S. S., \& Lepper, M. R. (2000). When is choice demotivating: Can one desire too much of a good thing?. Journal of Personality and Social Psychology, 79(6), 995-1006.

Jaakkola, E., \& Alexander, M. (2014). The role of customer engagement behaviour in value cocreation: a service system perspective. Journal of Service Research, 17(3), 247-261.

Kabadayi, S., Ali, F., Choi, H., Joosten, H. and Lu, C. (2019), "Smart service experience in hospitality and tourism services: A conceptualisation and future research agenda", Journal of Service Management, 30(3), 326-348.

Kang, S. (2014). Factors influencing intention of mobile application use. International Journal of Mobile Communications, 12(4), 360-379.

Kapser, S., \& Abdelrahman, M. (2020). Acceptance of autonomous delivery vehicles for lastmile delivery in Germany-Extending UTAUT2 with risk perceptions. Transportation Research Part C: Emerging Technologies, 111, 210-225.

Karjaluoto, H., Shaikh, A. A., Saarijärvi, H., \& Saraniemi, S. (2019). How perceived value drives the use of mobile financial services apps. International Journal of Information Management, 47, 252-261.

Kaushik, A. K., \& Rahman, Z. (2015). An alternative model of self-service retail technology adoption. Journal of Services Marketing, 29 (5), 406-420.

Kock, N. (2015). Common method bias in PLS-SEM: A full collinearity assessment approach. International Journal of e-Collaboration (IJEC), 11(4), 1-10. 
Kim, H. Y., Lee, J. Y., Mun, J. M., \& Johnson, K. K. (2017). Consumer adoption of smart in-store technology: assessing the predictive value of attitude versus beliefs in the technology acceptance model. International Journal of Fashion Design, Technology and Education, 10(1), 26-36.

Knoll, L. J., Magis-Weinberg, L., Speekenbrink, M., \& Blakemore, S. J. (2015). Social influence on risk perception during adolescence. Psychological Science, 26(5), 583-592.

Knote, R., Janson, A., Söllner, M., \& Leimeister, J. M. (2020). Value Co-Creation in Smart Services: A Functional Affordances Perspective on Smart Personal Assistants. Journal of the Association for Information Systems. (Forthcoming)

Liam O'Connell (2020), Global retail sales 2018-2022, Statista, https://www.statista.com/statistics/443522/global-retail-sales/

Leroi-Werelds, S. (2019), An update on customer value: state of the art, revised typology, and research agenda, Journal of Service Management, 30( 5), 650-680.

Lindell, M. K., \& Whitney, D. J. (2001). Accounting for common method variance in crosssectional research designs. Journal of Applied Psychology, 86(1), 114.

Lowry, P. B., \& Gaskin, J. (2014). Partial least squares (PLS) structural equation modeling (SEM) for building and testing behavioural causal theory: When to choose it and how to use it. IEEE transactions on professional communication, 57(2), 123-146.

Magner L (2016) Fast fashion in Australia. IBIS World, Melbourne

Marketing Science Institute. (2018). 2018-2020 Research Priorities.

Martin, H. S., \& Herrero, A. (2012). Influence of the user's psychological factors on the online purchase intention in rural tourism: Integrating innovativeness to the UTAUT framework. Tourism Management, 33(2), 341-350.

Meuter, M. L., Ostrom, A. L., Roundtree, R. I., \& Bitner, M. J. (2000). Self-service technologies: understanding customer satisfaction with technology-based service encounters. Journal of Marketing, 64(3), 50-64.

Müller-Seitz, G., Dautzenberg, K., Creusen, U., \& Stromereder, C. (2009). Customer acceptance of RFID technology: Evidence from the German electronic retail sector. Journal of Retailing and Consumer Services, 16(1), 31-39.

Negash, S., Ryan, T., \& Igbaria, M. (2003). Quality and effectiveness in web-based customer support systems. Information \& Management, 40(8), 757-768.

Nitzl, C., Roldan, J.L. and Cepeda, G. (2016), "Mediation analysis in partial least squares path modeling: Helping researchers discuss more sophisticated models", Industrial Management \& Data Systems, 116( 9), 1849-1864.

Novak, T. P., \& Hoffman, D. L. (2019). Relationship journeys in the Internet of things: a new framework for understanding interactions between consumers and smart objects. Journal of the Academy of Marketing Science, 47(2), 216-237.

O'Brien, H., \& Cairns, P. (2015). An empirical evaluation of the User Engagement Scale (UES) in online news environments. Information Processing \& Management, 51(4), 413-427. 
Overby, J. W., \& Lee, E. J. (2006). The effects of utilitarian and hedonic online shopping value on consumer preference and intentions. Journal of Business Research, 59(10-11), 11601166.

Park, Y. J., Heo, P. S., \& Rim, M. H. (2008). Measurement of a customer satisfaction index for improvement of mobile RFID services in Korea. Etri Journal, 30(5), 634-643.

Pardamean, B., \& Susanto, M. (2012). Assessing user acceptance toward blog technology using the UTAUT model. International Journal of Mathematics and Computers in Simulation, 1(6), 203-216.

Patil, P., Tamilmani, K., Rana, N. P., \& Raghavan, V. (2020). Understanding consumer adoption of mobile payment in India: Extending Meta-UTAUT model with personal innovativeness, anxiety, trust, and grievance redressal. International Journal of Information Management, 54, 102-144.

Pavlou, P. A., Liang, H., \& Xue, Y. (2006). Understanding and Mitigating Uncertainty in Online Environments: A Principal-agent Perspective. MIS Quarterly 31(1), 105-136.

Peng, S., Yang, A., Cao, L., Yu, S., \& Xie, D. (2017). Social influence modeling using information theory in mobile social networks. Information Sciences, 379, 146-159.

Petter, S., Straub, D., \& Rai, A. (2007). Specifying formative constructs in information systems research. MIS quarterly, 31 (4), 623-656.

Podsakoff, P. M., MacKenzie, S. B., Lee, J. Y., \& Podsakoff, N. P. (2003). Common method biases in behavioural research: a critical review of the literature and recommended remedies. Journal of Applied Psychology, 88(5), 879.

Precourt, G. (2016). How is consumer engagement reshaping marketing? Journal of Advertising Research, 56(1), 2-3.

Pöyry, E., Parvinen, P., Mattila, O., \& Holopainen, J. (2020). Engaged, but with what? Objects of engagement in technology-aided B2B customer interactions. Journal of Marketing Management, 36(3-4), 334-360.

Pynoo, B., Devolder, P., Tondeur, J., Van Braak, J., Duyck, W., \& Duyck, P. (2011). Predicting secondary school teachers' acceptance and use of a digital learning environment: A cross-sectional study. Computers in Human Behaviour, 27(1), 568-575.

Qin, L., Kim, Y., Hsu, J., \& Tan, X. (2011). The effects of social influence on user acceptance of online social networks. International Journal of Human-Computer Interaction, 27(9), 885-899.

Ringle, C. M., Wende, S., \& Becker, J. M. (2015). SmartPLS 3. Boenningstedt: SmartPLS GmbH. http://www. smartpls.com.

Roggeveen, A. L., Grewal, D., \& Schweiger, E. B. (2020). The DAST framework for retail atmospherics: The impact of in-and out-of-store retail journey touchpoints on the customer experience. Journal of Retailing, 96(1), 128-137.

Roy, S. K., Balaji, M. S., Quazi, A., \& Quaddus, M. (2018a). Predictors of customer acceptance of and resistance to smart technologies in the retail sector. Journal of Retailing and Consumer Services, 42, 147-160. 
Roy, S. K., Balaji, M. S., Soutar, G., Lassar, W. M., \& Roy, R. (2018b). Customer engagement behaviour in individualistic and collectivistic markets. Journal of Business Research, 86, 281-290.

Roy, S. K., Balaji, M. S., Sadeque, S., Nguyen, B., \& Melewar, T. C. (2017). Constituents and consequences of smart customer experience in retailing. Technological Forecasting and Social Change, 124, 257-270.

Roy, S. K., Balaji, M. S., \& Nguyen, B. (2020a). Consumer-computer interaction and in-store smart technology (IST) in the retail industry: the role of motivation, opportunity, and ability. Journal of Marketing Management, 36(3-4), 299-333.

Roy, S. K., Shekhar, V., Quazi, A., \& Quaddus, M. (2020b). Consumer engagement behaviours: do service convenience and organisational characteristics matter?. Journal of Service Theory and Practice, 30(2), 195-232.

Roy, S. K., Singh, G., Hope, M., Nguyen, B., \& Harrigan, P. (2019). The rise of smart consumers: role of smart servicescape and smart consumer experience co-creation. Journal of Marketing Management, 35(15-16), 1480-1513.

Sabherwal, R., Jeyaraj, A., \& Chowa, C. (2006). Information system success: Individual and organisational determinants. Management Science, 52(12), 1849-1864.

Sahu, A. K., Padhy, R. K., \& Dhir, A. (2020). Envisioning the future of behavioural decisionmaking: A systematic literature review of behavioural reasoning theory. Australasian Marketing Journal (AMJ )in press.

Sarstedt, M., Ringle, C. M., Cheah, J. H., Ting, H., Moisescu, O. I., \& Radomir, L. (2020). Structural model robustness checks in PLS-SEM. Tourism Economics, 26 (4), 531-554

Shaw, N., \& Sergueeva, K. (2019). The non-monetary benefits of mobile commerce: Extending UTAUT2 with perceived value. International Journal of Information Management, 45, 44-55.

Shin, D. H. (2015). Quality of experience: Beyond the user experience of smart services. Total Quality Management \& Business Excellence, 26(7-8), 919-932.

Soper, D.S., 2014. A-priori sample size calculator for structural equation models http://www.danielsoper.com/statcalc

Talukder, M., \& Quazi, A. (2011). The impact of social influence on individuals' adoption of innovation. Journal of Organizational Computing and Electronic Commerce, 21(2), 111135.

Tamilmani, K., Rana, N. P., \& Dwivedi, Y. K. (2020). Consumer acceptance and use of information technology: A meta-analytic evaluation of UTAUT2. Information Systems Frontiers, 1-19.

Taylor, S., \& Todd, P. A. (1995). Assessing IT usage: The role of prior experience. MIS Quarterly, 19(2), 561-570.

Tehseen, S., Ramayah, T., \& Sajilan, S. (2017). Testing and controlling for common method variance: A review of available methods. Journal of Management Sciences, 4(2), 142-168.

Tenenhaus, M., Vinzi, V. E., Chatelin, Y. M., \& Lauro, C. (2005). PLS path modeling. Computational Statistics \& Data Analysis, 48, 159-205. 
Vahdat, A., Alizadeh, A., Quach, S., \& Hamelin, N. (2020). Would you like to shop via mobile app technology? The technology acceptance model, social factors and purchase intention. Australasian Marketing Journal (AMJ), In press.

Valenzuela, S., Park, N., \& Kee, K. F. (2009). Is there social capital in a social network site?: Facebook use and college students' life satisfaction, trust, and participation. Journal of computer-mediated communication, 14(4), 875-901.

Vazquez, D., Dennis, C., \& Zhang, Y. (2017). Understanding the effect of smart retail brandConsumer communications via mobile instant messaging (MIM)-An empirical study in the Chinese context. Computers in Human Behaviour, 77, 425-436.

Van Doorn, J., Lemon, K. N., Mittal, V., Nass, S., Pick, D., Pirner, P., \& Verhoef, P. C. (2010). Customer engagement behaviour: Theoretical foundations and research directions. Journal of Service Research, 13(3), 253-266.

Venkatesh, V., Morris, M. G., Davis, G. B., \& Davis, F. D. (2003). User acceptance of information technology: Toward a unified view. MIS Quarterly, 27(3), 425-478.

Venkatesh, V., Thong, J. Y., \& Xu, X. (2012). Consumer acceptance and use of information technology: extending the unified theory of acceptance and use of technology. MIS Quarterly, 36(1), 157-178.

Venkatesh, V., Thong, J. Y., Chan, F. K., Hu, P. J. H., \& Brown, S. A. (2011). Extending the twostage information systems continuance model: Incorporating UTAUT predictors and the role of context. Information Systems Journal, 21(6), 527-555.

Viswanathan, V., Sese, F. J., \& Krafft, M. (2017). Social influence in the adoption of a B2B loyalty program: The role of elite status members. International Journal of Research in Marketing, 34(4), 901-918.

Vivek, S. D., Beatty, S. E., \& Morgan, R. M. (2012). Customer engagement: Exploring customer relationships beyond purchase. Journal of Marketing Theory and Practice, 20(2), 122-146.

Vrontis, D., Thrassou, A., \& Amirkhanpour, M. (2017). B2C smart retailing: A consumerfocused value-based analysis of interactions and synergies. Technological Forecasting and Social Change, 124, 271-282.

Wang, S. M., \& Lin, J. C. C. (2011). The effect of social influence on bloggers' usage intention. Online Information Review. 35 (1), 50-65.

Wang, R. J. H. (2020). Branded mobile application adoption and customer engagement behaviour. Computers in Human Behaviour. https://doi.org/10.1016/j.chb.2020.106245

Wells, J. D., Campbell, D. E., Valacich, J. S., \& Featherman, M. (2010). The effect of perceived novelty on the adoption of information technology innovations: a risk/reward perspective. Decision Sciences, 41(4), 813-843.

Weerakkody, V., El-Haddadeh, R., Al-Sobhi, F., Shareef, M. A., \& Dwivedi, Y. K. (2013). Examining the influence of intermediaries in facilitating e-government adoption: An empirical investigation. International Journal of Information Management, 33(5), 716725 
Weerakkody, V., Irani, Z., Kapoor, K., Sivarajah, U., \& Dwivedi, Y. K. (2017). Open data and its usability: an empirical view from the Citizen's perspective. Information Systems Frontiers, 19(2), 285-300.

Weijters, B., Rangarajan, D., Falk, T., \& Schillewaert, N. (2007). Determinants and outcomes of customers' use of self-service technology in a retail setting. Journal of Service Research, 10(1), 3-21.

Westaby, J. D. (2005). Behavioural reasoning theory: Identifying new linkages underlying intentions and behaviour. Organisational behaviour and human decision processes, 98(2), 97-120.

White, A., Breazeale, M., \& Collier, J. E. (2012). The effects of perceived fairness on customer responses to retailer SST push policies. Journal of Retailing, 88(2), 250-261.

Willems, K., Smolders, A., Brengman, M., Luyten, K., \& Schöning, J. (2017). The path-topurchase is paved with digital opportunities: An inventory of shopper-oriented retail technologies. Technological Forecasting and Social Change, 124, 228-242.

Wu, H. C., \& Cheng, C. C. (2018). What drives experiential loyalty toward smart restaurants? The case study of KFC in Beijing. Journal of Hospitality Marketing \& Management, 27(2), 151-177.

Wünderlich, N. V., Heinonen, K., Ostrom, A. L., Patricio, L., Sousa, R., Voss, C., \& Lemmink, J. G. (2015). "Futurising" smart service: implications for service researchers and managers. Journal of Services Marketing, 29 (6-7), 442-447

Yi, Y., Gong, T., Lee, H., 2013. The impact of other customers on customer citizenship behaviour. Psychology \& Marketing. 30 (4), 341-356.

Zhou, T., Lu, Y., \& Wang, B. (2010). Integrating TTF and UTAUT to explain mobile banking user adoption. Computers in Human Behaviour, 26(4), 760-767.

Zhao, X., Lynch Jr, J. G., \& Chen, Q. (2010). Reconsidering Baron and Kenny: Myths and truths about mediation analysis. Journal of Consumer Research, 37(2), 197-206.

Zuiderwijk, A., Janssen, M., \& Dwivedi, Y. K. (2015). Acceptance and use predictors of open data technologies: Drawing upon the unified theory of acceptance and use of technology. Government Information Quarterly, 32(4), 429-440.

\section{Appendix A: Study instruments for measuring SRT}

Novelty

1. [SRT] Stimulates my curiosity

2. [SRT] Arouses my imagination

3. [SRT] Made me feel interested in it

4. [SRT] Incited my inquisitiveness

\section{Effectiveness}

1. [SRT] allows me to have a more efficient shopping experience

2. [SRT] improves the productivity of my shopping experience

3. I find using a [SRT] can help me to have a smoother shopping experience 
4. Using [SRT] can improve my ability to easily complete a shopping trip.

\section{Interaction Quality}

1. Overall, I'd say the quality of my interaction with the [SRT] is excellent

2. I would say that the quality of my interaction with [SRT] is high

\section{Performance Expectancy}

1. I gain time using [SRT]

2. [SRT] optimises my shopping.

3. [SRT] allows me to make my shopping quicker.

4. Shopping will be more efficient using [SRT]

\section{Effort Expectancy}

1. Learning to use [SRT] is easy.

2. It's easy to use [SRT].

3. It's easy to use the [SRT] skilfully.

4. I do not have any doubts about what I'm doing when I'm using the [SRT]

Social Influence

1. My friends and peers expect me to use [SRT] in my shopping

2. People who influence my behaviour think that I should use [SRT]

3. I find [SRT] trendy.

4. The use of [SRT] gives me professional status.

5. My social environment expects me to use [SRT] in my shopping

6. People who are important to me think that I should adopt [SRT]

7. Most people I know using [SRT] frequently

\section{Facilitating Conditions}

1. I have all the necessary resources to use [SRT] during shopping.

2. I have the know-how to use [SRT]

3. If I have any doubts about how to use the [SRT], I can get help from the retail store.

4. If I have any doubts about how to use the [SRT], I do have a store employees and manager to help me

\section{Attitude}

How would you describe your feeling towards using smart retail technology in the retail store?

1. Unfavourable - Favourable

2. I dislike it $-\mathrm{I}$ like it

3. Bad-Good

\section{Customer Engagement Behaviour}

1. I would like to introduce [SRT] to others

2. I would speak favourably about the [SRT] to others

3. I would say positive things about the [SRT] to others.

4. I would assist other customers with the [SRT] if they need my help 
Copyright: (c) 2021 authors. This is an open-access article distributed under the terms of the Creative Commons Attribution-NonCommercial 3.0 Australia License, which permits noncommercial use, distribution, and reproduction in any medium, provided the original author and AJIS are credited.

doi: https://doi.org/10.3127/ajis.v25i0.2967

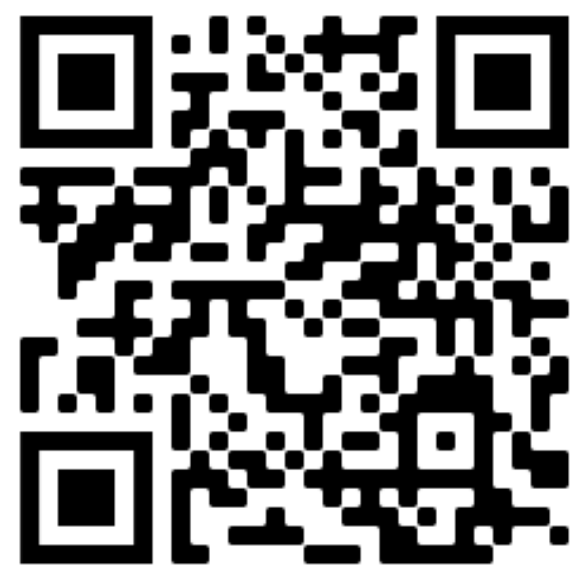

